\title{
A PROMETHEE Method Based Heuristic for Disassembly Line Balancing Problem
}

\author{
Shwetank Avikal* \\ Department of Mechanical Engineering, Graphic Era Hill University, Dehradun, India \\ P. K. Mishra \\ Department of Mechanical Engineering, Motilal Nehru National Institute of Technology, Allahabad, India
}

Rajeev Jain

Department of Mechanical Engineering, Kalaniketan Polytechnic College Jabalpur, Jabapur, India

H. C. Yadav

Department of Mechanical Engineering, Motilal Nehru National Institute of Technology, Allahabad, India

(Received: October 17, 2012 / Revised: February 4, 2013 / Accepted: August 16, 2013)

\begin{abstract}
Disassembly of discarded products takes place in the process of remanufacturing, recycling, and disposal. The disassembly lines have been taken as available choice for automated disassembly; therefore, it has become essential that it be designed and balanced to work efficiently. The multi-objective disassembly line balancing problem seeks to find a disassembly sequence which provides a feasible disassembly sequence, minimizes the number of workstations and idle time, and balances the line for the disassembly of post consumed product by considering the environment effects. This paper proposes a multi-criteria decision making technique based heuristic for assigning the disassembly tasks to the workstations. In the proposed heuristic, the PROMETHEE method is used for prioritizing the tasks to be assigned. The tasks are assigned to the disassembly workstations according to their priority rank and precedence relations. The proposed heuristic is illustrated with an example, and the results show that substantial improvement in the performance is achieved compared with other heuristics.
\end{abstract}

Keywords: Heuristic, Line Balancing, MCDM, PROMETHEE Method, Product Disassembly

* Corresponding Author, E-mail: avi.shwetank@gmail.com

\section{INTRODUCTION}

The average lifecycle of consumer products continues to decrease, and the systematic disposal of hazardous material, reuse of valuable parts or components, or recycling of pure material has become the main concern of disassembly. Industrial recycling and remanufacturing involves product disassembly to retrieve the desired parts and/or subassemblies by separating a product into its constituents, and it is gaining the importance due to increasing environmental and economic pressures. The disassembly line is the best choice for automated disassembly; therefore, it has become more important that the disassembly lines be designed and balanced so that it works as efficiently as possible (Gungor and Gupta, 1999b, 1999c; Lambert, 2003; McGovern and Gupta, 2003).

Product recovery aims to minimize the amount of waste that is sent to landfills after recovering valuable materials and parts from old or outdated products by means of recycling and remanufacturing (including reuse of parts and products). There are many attributes of a product that enhance product recovery such as ease of 
disassembly, modularity, type and compatibility of materials used, material identification markings, and efficient cross industrial reuse of common parts/materials. Disassembly is an important process in the product recovering process, and it allows for the selective separation of desired parts and materials. It has a high productivity and suitability for automation, and that is why the disassembly line is the most suitable layout for disassembly operations (Ilgin and Gupta, 2011; Guo et al., 2010; McGovern and Gupta, 2003).

Disassembly is virtually as old as mankind, and thus it is even older than assembly. The oldest part of disassembly comes from the retrieval of various parts of animals by humans for meat, but now this process is followed for post consumed product disassembly (Lambert and Gupta, 2005). Disassembly processing is the first vital stage in the recycling of manufactured products. Owing to the high productivity rates and strong adaptability of disassembly automation, the application of disassembly line has attracted much interest in the field of product disassembly. As an important topic in this field, the concept of disassembly line balancing focusing on minimizing the use of precious resources and maximizing the level of process capability in disassembly process is proposed and has recently received a great deal of attention in theoretical and practical terms. In recent years, disassembly has gained much attention due to the growing concerns of environmental legislation, public awareness, and economic attractiveness. In the quest for achieving higher productivity from the disassembly, automation of the process with a safe, efficient and economic heuristic has been considered as a potential field of interest (Ding et al., 2010; Tang and Zhou, 2006).

This paper proposes a multi-criteria decision making (MCDM) technique based heuristic for assigning the disassembly tasks to the workstations. In the proposed heuristic, the PROMETHEE method is used for prioritizing the tasks to be assigned. The tasks are assigned to the disassembly workstations according to their priority rank and precedence relations. The proposed heuristic is illustrated with an example.

The paper is organized as follows. Section 2 presents a brief literature review. Section 3 describes the computational procedure of PROMETHEE method, while Section 4 defines the problem formulation. Section 5 explains the proposed heuristic and the computational example is given in Section 6. Finally, Section 7 discuses the conclusion of this research work.

\section{LITERATURE REVIEW}

The problem of disassembly line balancing is much closer to assembly line balancing problems. Many researchers have discussed the solution of assembly line balancing problems. Baybars (1986) has developed a sin- gle pass heuristic for single-model deterministic line balancing, for different priority rules. Ghosh and Gagnon (1989) have reviewed a comprehensive literature and analyzed the design, balancing and scheduling of assembly system. They reviewed numerous quantitative and qualitative factors that could impact the design, balancing and scheduling of assembly systems which are organized into an eight-level hierarchical, factor/decision taxonomy. Askin and Zhou (1997) have proposed a nonlinear integer program as a model for mixed model line balancing problems with parallel workstations. Scholl and Klein (1999) have developed a branch and bound procedure to solve, either optimally or sub optimally, the problems with 297 tasks. Liu et al. (2003) have proposed two heuristics for solving the assembly line balancing problems. In proposed algorithm, an initial solution is generated by a bidirectional assignment procedure thereafter improvement is madeby swapping tasks among workstations. Boyson et al. (2007) have given a review of assembly line balancing problems. They have explained different line balancing problems. Bautista and Pereira (2009) have proposed a dynamic programming based heuristic for the assembly line balancing problems. Avikal et al. (2013) have proposed a critical path method (CPM)-based heuristic for U-shaped assembly line balancing problems.

The basic disassembly line balancing problem (DLBP) can be stated as the assignment of the tasks to the disassembly workstations such that all the precedence relations are satisfied and some measure of effectiveness is optimized. Altekin et al. (2008) have compared the operation and technical consideration of assembly and disassembly lines. This comparison has been given in Table 1 .

Gupta and Taleb (1994) explained what is considered the founding document in the science of disassembly planning and scheduling. Taleb et al. (1997) presented a follow-up paper where the issue of parts and materials commonality when scheduling disassembly is addressed. Gungor and Gupta (1999a) presented an especially thorough review of environmentally conscious manufacturing and product recovery. Gungor and Gupta (2001) proposed a disassembly line algorithm with the goal of assigning tasks to workstations in a way that probabilistically minimizes the cost of defective parts. Lambert (2003) provides a survey of the presently available literature on disassembly sequencing. Using a different approach, Torres et al. (2004) report a study for nondestructive automatic disassembly of personal computers.

McGovern and Gupta (2006) proposed ant colony optimization technique for disassembly sequencing with multiple objectives. The fact that, a simple DLBP is a NPcomplete problem and a genetic algorithm was presented by McGovern and Gupta (2007) to obtain optimal solutions of DLBP. Altekin et al. (2008) developed the mixed integer programming algorithm for the DLBP. Koc et al. (2009) have proposed two exact formulations for DLBPs 
Table 1. Comparison of assembly and disassembly line

\begin{tabular}{lll}
\hline \multicolumn{1}{c}{ Line consideration } & Assembly line & Disassembly line \\
\hline Demand & Dependent & Dependent \\
Demand sources & Single & Multiple \\
Demand entity & End product & Individual parts/subassemblies \\
Precedence relation & Yes & Yes \\
Complexity related to precedence relations & High & Moderate $^{\dagger}$ \\
Uncertainty related to quality of parts & Low & High \\
Uncertainty related to quantity of parts & Low & High \\
Uncertainty related to stations and material handling & Low to moderate & High \\
Reliability of the stations and material handling & High & Low \\
Multiple products & Yes & Yes \\
Flow process & Convergent & Divergent \\
Line flexibility & Low to moderate & High \\
Layout alternatives & Multiple & Multiple \\
Complexity of performance measures & Moderate & High \\
Known performance measures & Numerous & N/A \\
Complexity of "between stations inventory" & Moderate & High \\
Known technique for optimizations & Numerous & Few \\
Problem complexity & NP-hard & NP-hard \\
\hline
\end{tabular}

N/A: not applicable.

* Includes physical and functional precedence constraints, ${ }^{\dagger}$ mostly physical constraints.

with task precedence diagram construction using an AND/OR graph. Matsumoto et al. (2009) designed a methodology for manual disassembly works, and a creation method of a jig under the considering of labor cost. Ding et al. (2010) proposed a multi-objective DLBP and applied an ant colony algorithm for its solution. Guo et al. (2010) developed a mathematical model with the objective of minimizing the average total cost are constructed and solved the model with the help of Tabu search algorithm. Tsai and Nagaraj (2011) developed a mathematical model for the manufacturing firm who generates waste material during manufacturing process, and a disposal firm who collects and disposes the waste material. Avikal et al. (2013) have developed a heuristic for U-shaped DLBPs.

A number of researches have been reported in literature to balance the disassembly line. It includes development of heuristics, mathematical model and other solving techniques. A number of factors, such as part demand, part removal time, part hazard, etc., have been taken into consideration for the development of these heuristics. But these types of problems have not been solved by MCDM techniques. In the present work, the DLBP is considered as a MCDM problem. A PROMETHEE method based heuristic is developed to balance the disassembly line.

\section{PROMETHEE METHOD}

PROMETHEE is developed by Brans (1982) and further extended by Brans and Vincke (1985), and Brans and Mareschal (1994). It belongs to the methods of partial aggregation, or also called outranking methods, and was partly designed as a reaction to the complete aggregation MAUT methods (De Brucker et al., 2004). The evaluation table, where the alternatives are evaluated on the different criteria, is the starting point of the PROMETHEE method (Turcksin et al., 2011). The PROMETHEE method is known as an interactive MCDM approach designed to handle quantitative as well as qualitative criteria with discrete alternatives. In this method, pair-wise comparison of the alternatives is performed to compute a preference function for each criterion. On the basis of this preference function, a preference index for alternative $i$ over $i^{\prime}$ is determined. This preference index is the measure to support the hypothesis that alternative $i$ is preferred to $i^{\prime}$. The PROMETHEE method can classify the alternatives that are difficult to be compared because of a tradeoff relation of evaluation standards as non-comparable alternatives, and the PROMETHEE method has significant advantages over the other MCDM approaches (Athawale and Chakraborty, 2010). The PROMETHEE I method can provide the partial ordering of the decision alternatives, whereas PROMETHEE II method can derive the full ranking of the alternatives.

In this article, the PROMETHEE II method is employed to obtain the full ranking of the disassembly tasks that have to be assigned to the workstations. The procedural steps as involved in PROMETHEE II method are enlisted as follows (Athawale and Chakraborty, 2010; 
Doumpos and Zopounidis, 2004; Hajkowicz and Higgins, 2008):

Step 1. Normalize the decision matrix using the following equation:

$$
\begin{gathered}
N_{i j}=\left[Y_{i j}-\min \left(Y_{i j}\right)\right] /\left[\max \max \left(Y_{i j}\right)-\min \left(Y_{i j}\right)\right] \\
(\mathrm{i}=1,2, \cdots \mathrm{n} ; \mathrm{j}=1,2, \cdots, \mathrm{m})
\end{gathered}
$$

Where $X_{i j}$ is the performance measure of $i$-th alternative with respect to $j$-th criterion.

For non-beneficial criteria, Eq. (1) can be rewritten as follows:

$$
N_{i j}=\left[\max \left(Y_{i j}\right)-Y_{i j}\right] /\left[\max \max \left(Y_{i j}\right)-\min \left(Y_{i j}\right)\right]
$$

Step 2. Calculate the evaluative differences of $i$-th alternative with respect to other alternatives. This step involves the calculation of differences in criteria values between different alternatives pair-wise.

Step 3. Calculate the preference function, $P F_{j}\left(i, i^{\prime}\right)$.

There are six main types of generalized preference functions (Athawale and Chakraborty, 2010). But it may be difficult for the decision maker to specify which specific form of preference function is suitable for each criterion and also to determine the parameters involved. Athawale and Chakraborty (2010) proposed the following simplified preference functions:

$$
\begin{gathered}
P F_{j}\left(i, i^{\prime}\right)=0, \text { if } N_{i j} \leq N_{i^{\prime} j} \\
P F_{j}\left(i, i^{\prime}\right)=\left(N_{i j}-N_{i^{\prime} j}\right) \text {, if } N_{i j}>N_{i^{\prime} j}
\end{gathered}
$$

Step 4. Calculate the aggregated preference function taking into account the criteria priority.

Aggregated preference function,

$$
A P F\left(i, i^{\prime}\right)=\left[\sum_{j=i}^{m} w_{j} \times P F_{j}\left(i, i^{\prime}\right)\right] / \sum_{j=i}^{m} w_{j}
$$

where $w_{j}$ is the relative importance (priority) of $j$-th criterion.

Step 5. Determine the leaving and entering outranking flows as follows:
Leaving (or positive) flow for $i$-th alternative

$$
\beta^{+}(i)=\frac{1}{n-1} \sum_{i=1}^{n} A P F\left(i, i^{\prime}\right)
$$

Entering (or negative) flow for $i$-th alternative

$$
\beta^{-}(i)=\frac{1}{n-1} \sum_{i=1}^{n} A P F\left(i^{\prime}, i\right)
$$

where $n$ is the number of alternatives.

Here, each alternative faces $(n-1)$ number of other alternatives. The leaving flow expresses how much an alternative dominates the other alternatives, while the entering flow denotes how much an alternative is dominated by the other alternatives. Based on these outranking flows, the PROMETHEE II method can give the complete preorder by using a net flow.

Step 6. Calculate the net outranking flow for each alternative.

$$
\beta(i)=\beta^{+}(i)-\beta^{-}(i)
$$

Step 7. Determine the ranking of all the considered alternatives depending on the values of $\beta(i)$. The higher value of $\beta(i)$, the better is the alternative. Thus, the best alternative is the one having the highest $\beta(i)$ value.

\section{PROBLEM FORMULATION}

The heuristic has been developed for assigning the tasks to the disassembly workstation in such a way that the number of required disassembly workstations can be minimized, the idle time of the workstations and line can be minimized and balance the line. By achieving these objectives, some more objectives of disassembly line may be achieved which are much important than all the above objectives. These objectives may be removal of hazardous component before all other components, removal of high demand parts before low demand parts and removal of those parts first, which have higher part removal time than other parts. It seems to be very difficult to prioritize the task for disassembly process. To reduce these difficulties, a MCDM based heuristic has been proposed for prioritizing and assigning the tasks to the disassembly line workstations. Three criteria have been considered for DLBP on the basis of work done by McGovern and Gupta (2003). They are as follows:

1) Part demand: Disassembly of highly demanded parts should take place at the earliest workstation(s) possible since the longer they stay in the work-piece, the 
higher the chance of damaging them during the disassembly process. The parts with higher demand will be supplied to the customer at the time and it will also strengthens the disassembly system and develop relation with customer.

2) Disassembly time: It is necessary to assign high disassembly time tasks to the workstation such that the utilization of workstations is maximized. It also helps to achieve the minimum number of workstations for the disassembly process.

3) Part hazardous: Part with hazardous material contents should be removed from the work-piece as early as possible to reduce the possibility of hazardous material spill which could lead to the breakdown of a workstation and/or the breakdown of the materialhandling system and/or the contamination of the demanded parts.

In the case of DLBP, it is very difficult to select the tasks that are to be assigned to the workstation because of its MCDM nature. Therefore, numerous heuristics have been developed to select the task for assignment to the disassembly workstation with the help of priority rules, and some problem solving techniques except for the MCDM based technique have not been reported in this field. A PROMETHEE method has been used to solve this MCDM problem, and the tasks have been prioritized by PROMETHEE method and assigned to workstation according to their priority rank and precedence relations.

\section{PROPOSED HEURISTIC}

The proposed heuristic is based on the MCDM technique. This heuristic can be divided in three stages and five steps: 1) selecting the priority of each criterion, 2) application of PROMETHEE II method, and 3) assignment of the disassembly tasks to the workstations. In the first stage, the priority of each criterion is selected according to knowledge and previous experience (step 1). In the second stage, preference functions and parameter values are determined to enable the measurement of the contribution of the alternatives to the criteria. With this information, the evaluation table is constructed in step 2. Afterwards, the alternatives are evaluated and ranked by PROMETHEE II method in step 3. In the last stage, the disassembly tasks are assigned to the workstations according to their rank and precedence relation. Tasks are selected from their first rank in decreasing order, and assignments on workstations are made in step 4. If all the tasks have not assigned and no task is eligible for assignment on current workstation, then start a new workstation (step 5). The procedure is repeated till the assignments of all the tasks are made. The steps of the proposed heuristics are shown in Figure 1.

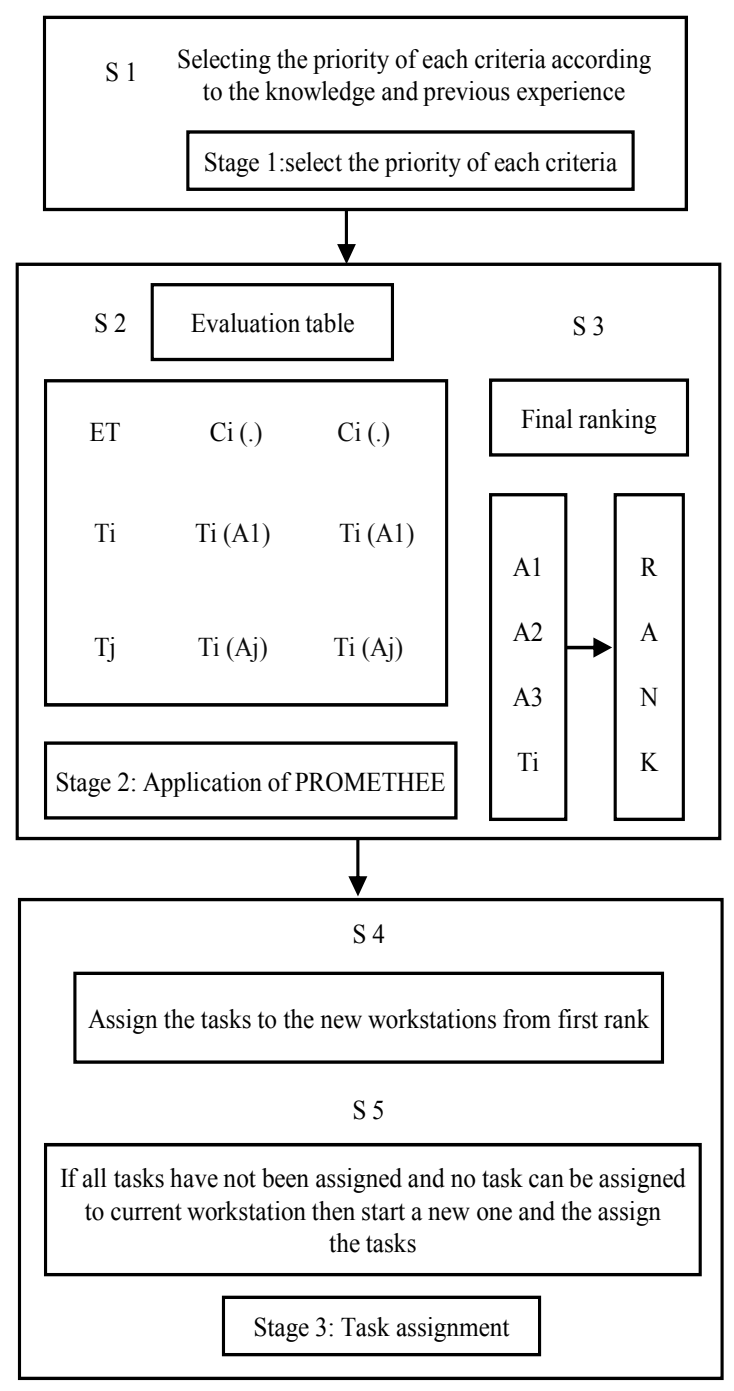

Figure 1. The PROMETHEE method based heuristic approach. S: step.

\section{COMPUTATIONAL EXAMPLE}

The developed algorithm is investigated in a variety of test cases to confirm its performance and to optimize parameters. The proposed heuristic is used to provide a solution to the DLBP based on the disassembly sequencing problem presented by Gupta et al. (2003) where the objective is to completely disassemble a given product (Figure 2) consisting of $n=10$ components and several precedence relationships (e.g., parts 5 and 6 need to be removed prior to part 7).

This practical and relevant example consists of the data for the disassembly of a product as shown in Table 2 . It consists of ten subassemblies with part removal times of $T_{k}=\{14,10,12,18,23,16,20,36,14,10\}$, hazardousness as $h_{k}=\{0,0,0,0,0,0,1,0,0,0\}$, part demand 


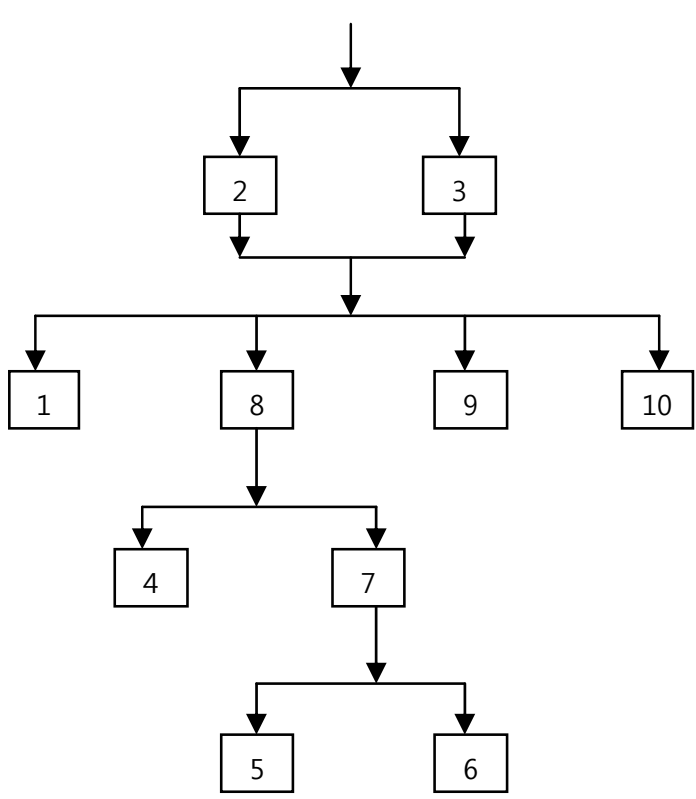

Figure 2. Example of product precedence relationships.

Table 2. Knowledge based of the example from literature

\begin{tabular}{cccr}
\hline Part & Time (s) & Hazardous & Demand \\
\hline 1 & 14 & 0 & 0 \\
2 & 10 & 0 & 500 \\
3 & 12 & 0 & 0 \\
4 & 18 & 0 & 0 \\
5 & 23 & 0 & 0 \\
6 & 16 & 0 & 750 \\
7 & 20 & 1 & 295 \\
8 & 36 & 0 & 0 \\
9 & 14 & 0 & 360 \\
10 & 10 & 0 & 0 \\
\hline
\end{tabular}

$d_{k}=\{0,500,0,0,0,750,295,0,360,0\}$. The disassembly line is operated at a speed that allows 40 seconds for each workstation.

\subsection{Selecting the Priority of Each Criteria}

The priority of each criterion is selected on the basis of knowledge and previous experience. Product hazardousness is selected as the highest priority criterion; product demand is selected as the next priority, and part removal time, i.e., task time is selected as last priority. The numerical value of priority for product hazardness is selected 3, 2 numerical value is selected for part demand and 1 is selected for task time. It can also be written as the ratios of each criterion are 3:2:1 in order of part hazardness, part demand, and task time.

\subsection{Determine the Rank of Tasks}

The final rank of the tasks is calculated by PROMETREE with the help of priority of alternatives that has been calculated based on knowledge and previous experience. The data for the DLBP listed in Table 2 is normalized by Eqs. (1) and (2) and listed in Table 3. The weight of each criterion is taken as mentioned in the above section.

Now, the preference functions are calculated for all the pairs of alternatives by Eqs. (3) and (4) and listed in Table 4.

Table 5 exhibits the aggregated preference function values for all the paired alternatives that are calculated by Eq. (5). The leaving and the entering flows for different location alternatives are now computed by using Eqs. (6) and (7) and listed in Table 6.

The net outranking flow values for different alternative locations and their relative rankings are calculated by Eq. (8) and listed in Table 7. Now, the tasks are arranged in descending order according to their net outranking flow values. This provides the applicability and potentiality of the PROMETHEE II method for solving complex decision-making problems in the disassembly domain.

\subsection{Assignment of the Tasks to the Workstations}

After assigning rank to all the tasks to be performed, the assignment of tasks to the workstation is started. Start the first workstation with the cycle time of 40 seconds, and check the rank list for the assignment of the tasks to the disassembly workstations. Task 7 has the first rank in the rank list, but it cannot be assigned because of its precedence relations so move to the next eligible tasks, i.e., tasks 2 and 3.

Table 3. Normalized data of modified knowledge base of PC example

\begin{tabular}{cccc}
\hline Task & $\begin{array}{c}\text { Part removal } \\
\text { time }(\mathrm{C} 1)\end{array}$ & $\begin{array}{c}\text { Part demand } \\
(\mathrm{C} 2)\end{array}$ & $\begin{array}{c}\text { Part hazardous } \\
(\mathrm{C} 3)\end{array}$ \\
\hline T1 & 0.080925 & 0 & 0 \\
T2 & 0.057803 & 0.262467 & 0 \\
T3 & 0.069364 & 0 & 0 \\
T4 & 0.104046 & 0 & 0 \\
T5 & 0.132948 & 0 & 0 \\
T6 & 0.092486 & 0.393701 & 0 \\
T7 & 0.115607 & 0.154856 & 1 \\
T8 & 0.208092 & 0 & 0 \\
T9 & 0.080925 & 0.188976 & 0 \\
T10 & 0.057803 & 0 & 0 \\
\hline
\end{tabular}


Table 4. Preference functions for all the pairs of alternatives

\begin{tabular}{|c|c|c|c|c|c|c|c|}
\hline Task & $\mathrm{C} 1$ & $\mathrm{C} 2$ & $\mathrm{C} 3$ & Task & $\mathrm{C} 1$ & $\mathrm{C} 2$ & $\mathrm{C} 3$ \\
\hline$(\mathrm{T} 1, \mathrm{~T} 2)$ & 0.023121 & 0 & 0 & $(\mathrm{~T} 6, \mathrm{~T} 1)$ & 0.011561 & 0.393701 & 0 \\
\hline (T1, T3) & 0.011561 & 0 & 0 & (T6, T2) & 0.034682 & 0.131234 & 0 \\
\hline$(\mathrm{T} 1, \mathrm{~T} 4)$ & 0 & 0 & 0 & (T6, T3) & 0.023121 & 0.393701 & 0 \\
\hline$(\mathrm{T} 1, \mathrm{~T} 5)$ & 0 & 0 & 0 & (T6, T4) & 0 & 0.393701 & 0 \\
\hline$(\mathrm{T} 1, \mathrm{~T} 6)$ & 0 & 0 & 0 & (T6, T5) & 0 & 0.393701 & 0 \\
\hline$(\mathrm{T} 1, \mathrm{~T} 7)$ & 0 & 0 & 0 & $(\mathrm{~T} 6, \mathrm{~T} 7)$ & 0 & 0.238845 & 0 \\
\hline$(\mathrm{T} 1, \mathrm{~T} 8)$ & 0 & 0 & 0 & (T6, T8) & 0 & 0.393701 & 0 \\
\hline (T1, T9) & 0 & 0 & 0 & (T6, T9) & 0.011561 & 0.204724 & 0 \\
\hline$(\mathrm{T} 1, \mathrm{~T} 10)$ & 0.023121 & 0 & 0 & $(\mathrm{~T} 6, \mathrm{~T} 10)$ & 0.034682 & 0.393701 & 0 \\
\hline$(\mathrm{T} 2, \mathrm{~T} 1)$ & 0 & 0.262467 & 0 & $(\mathrm{~T} 7, \mathrm{~T} 1)$ & 0.034682 & 0.154856 & 1 \\
\hline (T2, T3) & 0 & 0.262467 & 0 & $(\mathrm{~T} 7, \mathrm{~T} 2)$ & 0.057803 & 0 & 1 \\
\hline$(\mathrm{T} 2, \mathrm{~T} 4)$ & 0 & 0.262467 & 0 & $(\mathrm{~T} 7, \mathrm{~T} 3)$ & 0.046243 & 0.154856 & 1 \\
\hline (T2, T5) & 0 & 0.262467 & 0 & $(\mathrm{~T} 7, \mathrm{~T} 4)$ & 0.011561 & 0.154856 & 1 \\
\hline$(\mathrm{T} 2, \mathrm{~T} 6)$ & 0 & 0 & 0 & $(\mathrm{~T} 7, \mathrm{~T} 5)$ & 0 & 0.154856 & 1 \\
\hline$(\mathrm{T} 2, \mathrm{~T} 7)$ & 0 & 0.107612 & 0 & (T7, T6) & 0.023121 & 0 & 1 \\
\hline$(\mathrm{T} 2, \mathrm{~T} 8)$ & 0 & 0.262467 & 0 & (T7, T8) & 0 & 0.154856 & 1 \\
\hline$(\mathrm{T} 2, \mathrm{~T} 9)$ & 0 & 0.073491 & 0 & $(\mathrm{~T} 7, \mathrm{~T} 9)$ & 0.034682 & 0 & 1 \\
\hline$(\mathrm{T} 2, \mathrm{~T} 10)$ & 0 & 0.262467 & 0 & $(\mathrm{~T} 7, \mathrm{~T} 10)$ & 0.057803 & 0.154856 & 1 \\
\hline$(\mathrm{T} 3, \mathrm{~T} 1)$ & 0 & 0 & 0 & $(\mathrm{~T} 8, \mathrm{~T} 1)$ & 0.127168 & 0 & 0 \\
\hline$(\mathrm{T} 3, \mathrm{~T} 2)$ & 0.011561 & 0 & 0 & $(\mathrm{~T} 8, \mathrm{~T} 2)$ & 0.150289 & 0 & 0 \\
\hline$(\mathrm{T} 3, \mathrm{~T} 4)$ & 0 & 0 & 0 & (T8, T3) & 0.138728 & 0 & 0 \\
\hline (T3, T5) & 0 & 0 & 0 & $(\mathrm{~T} 8, \mathrm{~T} 4)$ & 0.104046 & 0 & 0 \\
\hline$(\mathrm{T} 3, \mathrm{~T} 6)$ & 0 & 0 & 0 & $(\mathrm{~T} 8, \mathrm{~T} 5)$ & 0.075145 & 0 & 0 \\
\hline$(\mathrm{T} 3, \mathrm{~T} 7)$ & 0 & 0 & 0 & $(\mathrm{~T} 8, \mathrm{~T} 6)$ & 0.115607 & 0 & 0 \\
\hline (T3, T8) & 0 & 0 & 0 & $(\mathrm{~T} 8, \mathrm{~T} 7)$ & 0.092486 & 0 & 0 \\
\hline$(\mathrm{T} 3, \mathrm{~T} 9)$ & 0 & 0 & 0 & $(\mathrm{~T} 8, \mathrm{~T} 9)$ & 0.127168 & 0 & 0 \\
\hline (T3, T10) & 0.011561 & 0 & 0 & $(\mathrm{~T} 8, \mathrm{~T} 10)$ & 0.150289 & 0 & 0 \\
\hline$(\mathrm{T} 4, \mathrm{~T} 1)$ & 0.023121 & 0 & 0 & $(\mathrm{~T} 9, \mathrm{~T} 1)$ & 0 & 0.188976 & 0 \\
\hline$(\mathrm{T} 4, \mathrm{~T} 2)$ & 0.046243 & 0 & 0 & $(\mathrm{~T} 9, \mathrm{~T} 2)$ & 0.023121 & 0 & 0 \\
\hline$(\mathrm{T} 4, \mathrm{~T} 3)$ & 0.034682 & 0 & 0 & (T9, T3) & 0.011561 & 0.188976 & 0 \\
\hline$(\mathrm{T} 4, \mathrm{~T} 5)$ & 0 & 0 & 0 & $(\mathrm{~T} 9, \mathrm{~T} 4)$ & 0 & 0.188976 & 0 \\
\hline$(\mathrm{T} 4, \mathrm{~T} 6)$ & 0.011561 & 0 & 0 & (T9, T5) & 0 & 0.188976 & 0 \\
\hline$(\mathrm{T} 4, \mathrm{~T} 7)$ & 0 & 0 & 0 & (T9, T6) & 0 & 0 & 0 \\
\hline$(\mathrm{T} 4, \mathrm{~T} 8)$ & 0 & 0 & 0 & $(\mathrm{~T} 9, \mathrm{~T} 7)$ & 0 & 0.034121 & 0 \\
\hline$(\mathrm{T} 4, \mathrm{~T} 9)$ & 0.023121 & 0 & 0 & (T9, T8) & 0 & 0.188976 & 0 \\
\hline$(\mathrm{T} 4, \mathrm{~T} 10)$ & 0.046243 & 0 & 0 & $(\mathrm{~T} 9, \mathrm{~T} 10)$ & 0.023121 & 0.188976 & 0 \\
\hline$(\mathrm{T} 5, \mathrm{~T} 1)$ & 0.052023 & 0 & 0 & $(\mathrm{~T} 10, \mathrm{~T} 1)$ & 0 & 0 & 0 \\
\hline$(\mathrm{T} 5, \mathrm{~T} 2)$ & 0.075145 & 0 & 0 & $(\mathrm{~T} 10, \mathrm{~T} 2)$ & 0 & 0 & 0 \\
\hline (T5, T3) & 0.063584 & 0 & 0 & $(\mathrm{~T} 10, \mathrm{~T} 3)$ & 0 & 0 & 0 \\
\hline$(\mathrm{T} 5, \mathrm{~T} 4)$ & 0.028902 & 0 & 0 & $(\mathrm{~T} 10, \mathrm{~T} 4)$ & 0 & 0 & 0 \\
\hline$(\mathrm{T} 5, \mathrm{~T} 6)$ & 0.040462 & 0 & 0 & $(\mathrm{~T} 10, \mathrm{~T} 5)$ & 0 & 0 & 0 \\
\hline$(\mathrm{T} 5, \mathrm{~T} 7)$ & 0.017341 & 0 & 0 & $(\mathrm{~T} 10, \mathrm{~T} 6)$ & 0 & 0 & 0 \\
\hline$(\mathrm{T} 5, \mathrm{~T} 8)$ & 0 & 0 & 0 & $(\mathrm{~T} 10, \mathrm{~T} 7)$ & 0 & 0 & 0 \\
\hline$(\mathrm{T} 5, \mathrm{~T} 9)$ & 0.052023 & 0 & 0 & $(\mathrm{~T} 10, \mathrm{~T} 8)$ & 0 & 0 & 0 \\
\hline$(\mathrm{T} 5, \mathrm{~T} 10)$ & 0.075145 & 0 & 0 & $(\mathrm{~T} 10, \mathrm{~T} 9)$ & 0 & 0 & 0 \\
\hline
\end{tabular}


Table 5. Aggregated preference function

\begin{tabular}{|c|c|c|c|c|c|c|c|c|c|c|}
\hline Task & $\mathrm{T} 1$ & $\mathrm{~T} 2$ & $\mathrm{~T} 3$ & $\mathrm{~T} 4$ & T5 & T6 & $\mathrm{T} 7$ & $\mathrm{~T} 8$ & T9 & $\mathrm{T} 10$ \\
\hline $\mathrm{T} 1$ & 0.0000 & 0.0046 & 0.0023 & 0.0000 & 0.0000 & 0.0000 & 0.0000 & 0.0000 & 0.0000 & 0.0046 \\
\hline $\mathrm{T} 2$ & 0.1050 & 0.0000 & 0.1050 & 0.1050 & 0.1050 & 0.0000 & 0.0430 & 0.1050 & 0.0294 & 0.1050 \\
\hline $\mathrm{T} 3$ & 0.0000 & 0.0023 & 0.0000 & 0.0000 & 0.0000 & 0.0000 & 0.0000 & 0.0000 & 0.0000 & 0.0023 \\
\hline $\mathrm{T} 4$ & 0.0046 & 0.0093 & 0.0069 & 0.0000 & 0.0000 & 0.0023 & 0.0000 & 0.0000 & 0.0046 & 0.0093 \\
\hline $\mathrm{T} 5$ & 0.0104 & 0.0150 & 0.0127 & 0.0058 & 0.0000 & 0.0081 & 0.0035 & 0.0000 & 0.0104 & 0.0150 \\
\hline $\mathrm{T} 6$ & 0.1598 & 0.0594 & 0.1621 & 0.1575 & 0.1575 & 0.0000 & 0.0955 & 0.1575 & 0.0842 & 0.1644 \\
\hline $\mathrm{T} 7$ & 0.6689 & 0.6116 & 0.6712 & 0.6643 & 0.6619 & 0.6046 & 0.0000 & 0.6619 & 0.6069 & 0.6735 \\
\hline $\mathrm{T} 8$ & 0.0254 & 0.0301 & 0.0278 & 0.0208 & 0.0150 & 0.0231 & 0.0185 & 0.0000 & 0.0254 & 0.0301 \\
\hline T9 & 0.0756 & 0.0046 & 0.0779 & 0.0756 & 0.0756 & 0.0000 & 0.0137 & 0.0756 & 0.0000 & 0.0802 \\
\hline $\mathrm{T} 10$ & 0.0000 & 0.0000 & 0.0000 & 0.0000 & 0.0000 & 0.0000 & 0.0000 & 0.0000 & 0.0000 & 0.0000 \\
\hline
\end{tabular}

Table 6. Leaving and entering flows for different tasks

\begin{tabular}{ccc}
\hline Task & Leaving flow & Entering flow \\
\hline T1 & 0.01156 & 1.04971 \\
T2 & 0.70236 & 0.73689 \\
T3 & 0.00462 & 1.06590 \\
T4 & 0.03699 & 1.02890 \\
T5 & 0.08092 & 1.01503 \\
T6 & 1.19792 & 0.63815 \\
T7 & 5.82483 & 0.17420 \\
T8 & 0.21618 & 1.00000 \\
T9 & 0.47875 & 0.76100 \\
T10 & 0.00000 & 1.08439 \\
\hline
\end{tabular}

Now task 2 is eligible for the assignment, so assign task 2 on the first workstation and move to another task. The next eligible task according to precedence relation is only 3 and no other is eligible, so assign task 3 to the current workstations. Now the station load on the first workstation has become 22 seconds because of assignment of tasks 2 and 3, and now four tasks are eligible for the assignment. Task 9 is on the top of the eligible task rank list, and it can be assigned to the current workstation because of its 14 seconds task time, and the idle time of the workstation is 18 seconds. After assignment of the task 9 to the first workstation, no other task can be assigned to the same workstation because of its 4 seconds idle time, so start a new workstation and assign the tasks to the workstations according to the same procedure. The tasks are assigned to the workstations as follows: $\mathrm{W} 1=\{2,3,9\}, \mathrm{W} 2=\{8\}, \mathrm{W} 3=\{7,6\}, \mathrm{W} 4=\{5,1\}$, and $W 5=\{4,10\}$. The idle times of all the workstations are: $I 1=\{4\}, I 2=\{4\}, I 3=\{4\}, I 4=\{4\}$, and I5 $=\{12\}$ (Table 8).
Table 7. Net outranking flow values for different tasks

\begin{tabular}{ccc}
\hline Task & Net outranking flow & Rank \\
\hline T1 & -1.03815 & 8 \\
T2 & -0.03452 & 3 \\
T3 & -1.06127 & 9 \\
T4 & -0.99191 & 7 \\
T5 & -0.93410 & 6 \\
T6 & 0.55977 & 2 \\
T7 & 5.65064 & 1 \\
T8 & -0.78382 & 5 \\
T9 & -0.28224 & 4 \\
T10 & -1.08439 & 10 \\
\hline
\end{tabular}

Table 8. Assignment of the tasks to the workstations

\begin{tabular}{cccc}
\hline Workstation & $\begin{array}{c}\text { Task } \\
\text { number }\end{array}$ & Task time & Idle time \\
\hline \multirow{3}{*}{ W1 } & 2 & 10 & 30 \\
& 3 & 12 & 18 \\
W2 & 9 & 14 & 4 \\
W3 & 8 & 36 & 4 \\
& 7 & 20 & 20 \\
W4 & 6 & 16 & 4 \\
& 5 & 23 & 17 \\
W5 & 1 & 14 & 3 \\
& 4 & 18 & 22 \\
\hline
\end{tabular}

After assigning all the tasks to the workstation "table 8 ", it has been found that proposed heuristic requires five workstations only, those are the same as the workstations required by the heuristic proposed by McGovern and Gupta (2003), but the average idle time of the worksta- 
tions increases. It can be seen that at the $100 \%$ cycle efficiency, the proposed heuristic can reduce the cycle time by 4 seconds, and it can reach up to 36 seconds, while the heuristic proposed by McGovern and Gupta (2003) can reduce the cycle time by only one second and reach up to 39 seconds. These findings led us to conclude that the proposed heuristic performs well and improves on the results provided by the heuristic proposed by McGovern and Gupta (2003).

\section{CONCLUSIONS}

The practice of industrial recycling and remanufacturing is growing in importance due to increasing environmental and economic pressures. Disassembly for reuse and recycling purposes is an emerging field of research that has many advantages over such traditional methods as shredding. The conventional challenge for the disassembly line balancing is the assignment of task to the disassembly work stations, and the assignment should be optimal in some sense so as to minimize the number of workstations, cycle time, idle time, line efficiency, and optimize the smoothing index, etc. In this case the author tries to minimize the cycle time of the line and maintain the same amount of idle time at all the workstations. The proposed heuristic was compared to another conventional heuristic, and the results showed that it reduces the cycle time of the line and balances the idle time of workstations.

In this article, an efficient, near optimal, multi-objective heuristic is presented for disassembly line balancing. The proposed heuristic is able to achieve all of the objectives and provide an efficient solution with minimum number of workstations. The heuristic provides the better results in idle time and cycle time of the workstations as compared to the heuristic proposed by McGovern and Gupta (2003). The proposed heuristic achieves all the objectives and also reduces the cycle time of the disassembly line. The implementation of the concept of MCDM in disassembly line performs better, and different MCDM techniques can be applied for making disassembly lines safer, efficient and cost effective. In the future work, some more criteria can be selected for the ranking and assignment of tasks to the workstations, and some other ranking methods can also be applied such as TOPSIS, ELECTRE for the ranking of the tasks.

\section{REFERENCES}

Altekin, F. T., Kandiller, L., and Ozdemirel, N. E. (2008), Profit-oriented disassembly-line balancing, International Journal of Production Research, 46(10), 2675 $-2693$.

Askin, R. G. and Zhou, M. (1997), A parallel station heu- ristic for the mixed-model production line balancing problem, International Journal of Production Research, 35(11), 3095-3106.

Athawale, V. M. and Chakraborty, S. (2010), Facility location selection using PROMETHEE II Method, Proceedings of the 2010 International Conference on Industrial Engineering and Operations Management, Dhaka, Bangladesh, 59-64.

Avikal, S., Jain, R., and Mishra, P. K. (2013), A heuristic for U-shaped disassembly line balancing problems, MIT Journal of Mechanical Engineering, 3(1), 51-56.

Avikal, S., Jain, R., Mishra, P. K., and Yadav, H. C. (2013), A heuristic for U-shaped assembly line balancing to improve labor productivity, Computer \& Industrial Engineering, 64(4), 895-901.

Bautista, J. and Pereira, J. (2009), A dynamic programming based heuristic for the assembly line balancing problem, European Journal of Operational Research, 194(3), 787-794.

Baybars, I. (1986), An efficient heuristic method for the simple assembly line balancing problem, International Journal of Production Research, 24(1), 149166.

Boyson, N., Fliedner, M., and Scholl, A. (2007), A classification of assembly line balancing problems, European Journal of Operational Research, 183(2), 674693.

Brans, J. P. (1982), L'ingénierie de la d ecision. Elaboration d'instruments d'aide à la décision. Methode PROMETHEE. In: Nadeau, R., Landry, M. (Eds.), L'aide à la décision: Nature, Instruments et Perspectives d'Avenir, Presses de 1 Universit e Laval, Qu ébec, Canada, 183-214.

Brans, J. P. and Mareschal, B. (1994), The PROMCALC and GAIA decision support system for MCDA, Decision Support Systems, 12(4-5), 297-310.

Brans, J. P. and Vincke, Ph. (1985), A preference ranking organization method: the PROMETHEE method for multiple criteria decision-making, Management Science, 31(6), 647-656.

Brennan L., Gupta, S. M., and Taleb, K. N. (1994). Operations planning issues in assembly/disassembly environment, International Journal of Operations and Production Management, 14 (9), 57-67.

De Brucker, K., Verbeke, A., and Macharis, C. (2004), The applicability of multicriteria-analysis to the evaluation of intelligent transport systems (ITS), Research in Transportation Economics, 8(1), 151-179.

Ding, L. P., Feng, Y. X., Tan, J. R., and Gao, Y. C. (2010), A new multi-objective ant colony algorithm for solving the disassembly line balancing problems, International Journal of Advance Manufacturing Technology, 48(5-8), 761-771.

Doumpos, M. and Zopounidis, C. (2004), A multi-criteria classification approach based on pair-wise compari- 
son, European Journal of Operational Research, 158(2), 378-389.

Ghosh, S. and Gagnon, R. J. (1989), A comprehensive literature review and analysis of the design, balancing and scheduling of assembly systems, International Journal of Production Research, 27(4), 637670.

Gungor, A. and Gupta, S. M. (1999a), Issues in environmentally conscious manufacturing and product recovery: a survey, Computer \& Industrial Engineering, 36(4), 811-853.

Gungor, A. and Gupta, S. M. (1999b), Disassembly line balancing, Proceedings of the 1999 Annual Meeting of the Northeast Decision Sciences Institute, Newport, RI, 193-195.

Gungor, A. and Gupta, S. M. (1999c), A systematic solution approach to the disassembly line balancing problem, Proceedings of the 25th International Conference on Computers and Industrial Engineering, New Orleans, LA, 70-73.

Gungor, A. and Gupta, S. M. (2001), A solution approach to the disassembly line problem in the presence of task failures, International journal of production research, 39(7), 1427-1467.

Guo, J., Ko, Y. D., and Hwang, H. (2010), A manufacturing/remanufacturing system with the consideration of required quality of end-of-used products, Industrial Engineering and Manufacturing System, 9(3), 204-214.

Gupta, S. M., McGovern, S. M., and Kamarthi, S. V. (2003), Solving disassembly sequence planning problems using combinatorial optimization, Proceedings of the 2003 Northeast Decision Sciences Institute Conference, Providence, RI, 178-180.

Gupta, S. M. and Taleb, K. N. (1994), Scheduling disassembly, International Journal of Production Research, 32(8), 1857-1866.

Hajkowicz, S. and Higgins, A. (2008), A comparison of multiple criteria analysis techniques for water resource management, European Journal of Operational Research, 184(1), 255-265.

Ilgin, M. A. and Gupta, S. M. (2011), Recovery of sensor embedded washing machines using a multi-kanban controlled disassembly line, Robotics and ComputerIntegrated Manufacturing, 27(2), 318-334.

Koc, A., Sabuncuoglu, I., and Erel, E. (2009), Two exact formulations for disassembly line balancing problems with task precedence diagram construction using an AND/OR graph, IIE Transactions, 41(10), 866-881.

Lambert, A. J. D. (2003), Disassembly sequencing: a survey, International Journal of Production Research,
41(16), 3721-3759.

Lambert, A. J. D. and Gupta, S. M. (2005), Disassembly Modeling for Assembly, Maintenance, Reuse, and Recycling, CRC Press, Boca Raton, FL.

Liu, S. B., Ong, H. L., and Huang, H. C. (2003), Two bidirectional heuristics for heuristics for the assembly line type II problem, International Journal of Advanced Manufacturing Technology, 22(9-10), 656-661.

Matsumoto, T., Yahata, Y., and Shida, K. (2009), Design of a method for disassembly works on recycle products, Industrial Engineering and Manufacturing System, 8(1), 66-71.

McGovern, S. M. and Gupta, S. M. (2003), 2-Opt heuristic for the disassembly line balancing problem, Proceedings of the SPIE International Conference on Environmentally Conscious Manufacturing III, Providence, RI, 71-84.

McGovern, S. M. and Gupta, S. M. (2006), Ant colony optimization for disassembly sequencing with multiple objectives, International Journal of Advance Manufacturing Technology, 30(5-6), 481-496.

McGovern, S. M. and Gupta, S. M. (2007), Combinatorial optimization analysis of the unary NP-complete disassembly line balancing problem, International Journal of Production Research, 45(18-19), 44854511.

Scholl, A. and Klein, R. (1999), ULINO: optimally balancing U-shaped JT assembly lines, International Journal of Production Research, 37(4), 721-736.

Taleb, K. N., Gupta, S. M., and Brennan, L. (1997), Disassembly of complex product structures with parts and materials commonality, Production Planning \& Control: The Management of Operations, 8(3), 255269.

Tang, Y. and Zhou, M. C. (2006), A systematic approach to design and operation of disassembly lines, IEEE Transactions on Automation Science and Engineering, 3(3), 324-329.

Torres, F., Gil, P., Puente, S. T., Pomares, J., and Aracil, R. (2004), Automatic PC disassembly for component recovery, International Journal of Advanced Manufacturing Technology, 23(1-2), 39-46.

Tsai, C. Y. and Nagaraj, S. E. (2011), Waste disposal models for manufacturing firm and disposal firm, Industrial Engineering and Manufacturing System, 10(2), 115-122.

Turcksin, L., Bernardini, A., and Macharis, C. (2011), A combined AHP-PROMETHEE approach for selecting the most appropriate policy scenario to stimulate a clean vehicle fleet, Procedia: Social and Behavioral Sciences, 20, 954-965. 